\title{
The College Life Experiences of African American Women Athletes ${ }^{1}$
}

\author{
Robert M. Sellers ${ }^{2}$ \\ University of Michigan \\ Gabriel P. Kuperminc \\ Georgia State University \\ Alphonse Damas, Jr. \\ University of Virginia
}

The present study provides a descriptive analysis of four areas of African American women student athletes' college life experiences: academic performance; alienation and abuse; perceived social advantage as the result of athletics; and life satisfaction. Multivariate comparisons were made between the four areas of college life experiences of 154 African American women student athletes and 793 White women student athletes, 250 African American women nonathletes, and 628 African American men student athletes from a national sample of 39 NCAA Division I universities. Overall, African American women student athletes are performing adequately academically, integrating socially within the university, perceiving some social advantage as the result of being athletes, and are fairly satisfied with their life. Their experiences seem most consistent with African American women nonathletes. Results are discussed in the context of potential policy recommendations as well as the need for more research on this particular population.

KEY WORDS: African American; athletics; black; sport; student athlete, women.

'The present study was made possible through the cooperation of the National Collegiate Athletic Association. However, all conclusions and recommendations are made solely by the authors and do not represent the views of the officers, staff, or the membership of the NCAA. The authors also express their gratitude to all of the students who participated in the studies. ${ }^{2}$ All correspondence should be directed to Robert M. Sellers, Department of Psychology, East Hall, University of Michigan, Ann Arbor, Michigan 48109.

699

0691-056297/1000-0699\$12.50/0 O 1997 Plenum Publishing Corporation 
Three important tenets of community psychology research are (a) to include groups who have historically been ignored in the research process; (b) to investigate how the person and the social ecology interact to influence behavior; and (c) to use research to inform social policy in hopes of making a change in the lives of the people which we study. The present study attempts to accomplish all three goals by investigating the college life experiences of African American women athletes. The present study presents an empirical, descriptive analysis of their socioeconomic and educational backgrounds as well as four areas of their college life experiences. The four areas examined include academic performance, alienation and abuse, perceptions of social advantage, and satisfaction.

\section{Dearth of Research on African American Women Student Athletes}

Studies of the life experiences of African American female athletes are virtually nonexistent. Although African American female athletes are often included within the samples of studies focusing on African American athletes and female athletes, results of these studies are seldom interpreted with the African American female athlete in mind. Our literature review revealed only two empirical studies that focused specifically on the college life experiences of African American women student athletes (see Evans \& Quarterman, 1983; Prakasa Rao \& Overman, 1984). Studies of African American athletes' collegiate experiences have typically focused on African American men. When studies include both male and female, there is a tendency to ignore gender differences (e.g., Center for the Study of Athletics, 1989a). Similarly, studies of women athletes' life experiences have typically focused on White women. Those studies that have used a racially diverse sample have tended to ignore race differences in the experiences of women athletes (e.g., Center for the Study of Athletics, 1989b). Thus, the current research literature represents a de facto assumption that the life experiences of African American female athletes do not differ in meaningful ways from either African American male athletes or White female athletes. However, some researchers question this assumption of uniformity of athletic experience across gender and race (see Bird \& Cripe, 1986; Corbett \& Johnson, 1993; Duda \& Allison, 1990).

\section{College Life Experience and Academic Performance}

Consistent with the conceptual work of Bell (1986), Bronfenbrenner and Crouter (1982), and Seidman (1991), the present research views student athletes' college life experiences as a mediating factor in the relationship 
between protective/risk factors (such as gender, race, socioeconomic background) and important social outcomes (such as graduation, upward social mobility, and psychological well-being). The college life experience represents the ecological context that student athletes encounter during their stay on campus. Although research examining student athletes' college life experience is sparse, there is a substantial body of research investigating the relationship between nonathletic students' perceptions and experiences on campus and their academic performance. A number of investigations have linked college life experiences outside of the classroom to college students' persistence rates and overall academic performance (e.g., Defour \& Hirsch, 1990; Nettles \& Johnson, 1987; Stage, 1988, 1989; Stoecker, Pascarella, \& Wolfle, 1988; Terenzini \& Pascarella, 1978; Tracey \& Sedlacek, 1984). Within this literature, a number of theoretical and empirical models have been presented to explain students' present college experiences as well as their academic background in determining academic outcomes. Within this research, evidence of gender and race differences with regard to college experiences and their influence on students' academic performance has been found (e.g., Nettles \& Johnson, 1987). For example, social and academic integration in the university community seem especially critical to the academic success of African American students (Allen, 1985; Loo \& Rolison, 1986). To fully understand the impact the ecological context has on the academic and psychological functioning of African American women student athletes, an examination of their on-campus life experiences is needed.

\section{Social Policies Affecting African American Women Student Athletes}

African American women student athletes are at the center of the two most important issues facing intercollegiate athletics in the 1990s: (a) the enforcement of Title IX, a federal regulation prohibiting sex discrimination in educational institutions; and (b) the academic reform movement within the National Collegiate Athletic Association (NCAA). Pressure from congress and the Justice Department has forced institutions to ensure that their intercollegiate athletic programs comply with Title IX. Title IX mandates that any educational institution receiving federal funds must provide equal educational opportunities, including intercollegiate athletics, for both men and women. The enforcement of Title IX should provide greater opportunities for women in athletics. Meanwhile, a reform movement within the National Collegiate Athletic Association (NCAA) has attempted to enhance the academic viability of student athletes by raising initial eligibility requirements (i.e., SAT and high school grade point average) for potential student athletes. African American student athletes are disproportionately 
excluded from the opportunity of an athletic scholarship as a result of the reform legislation (McArdle \& Hamagami, 1994; NCAA, 1991).

It is an open question as to which social policy has the greatest impact on African American women student athletes. The dearth of research on African American women student athletes makes evaluation of the impact of both gender equity and academic reform legislation on African American women student athletes' experiences tenuous. A baseline description of the social ecological experience of African American student athletes provides an important reference from which to evaluate the impact of future social policy.

\section{Review of Literature on Race, Gender, and Athletic Status Differences in College Experiences}

Although there is little research directly examining the college experiences of African American women student athletes, researchers have found important race, gender, and athletic status differences in experiences. This research provides direction for the present investigation on four areas of college life experience.

Academic Performance. The research literature on precollege predictors of student athletes' academic performance has reported gender and race differences in overall academic performance. There are significant race differences in both academic background and college academic performance for student athletes. African American student athletes come from poorer educational backgrounds than their White counterparts (Center for the Study of Athletics, 1989a; Sellers, Kuperminc, \& Waddell, 1991), and once in college, they perform less well academically (e.g., Ervin, Saunders, Gillis, \& Hogrebe, 1985; Kiger \& Lorentzen, 1986; Purdy, Eitzen, \& Hufnagel, 1982; Sellers, 1992; Shapiro, 1984). With respect to gender differences, female athletes achieve higher grade-point averages (Center for the Study of Athletics, 1989b; Kiger \& Lorentzen, 1986) and graduate at a higher rate than male athletes (NCAA, 1995). Graduation data specifically on African American women athletes are consistent with previous findings of race and gender differences in academic performance. African American women student athletes graduate at a rate of $49 \%$ which is considerably lower than the graduation rate of $69 \%$ for White women athletes (NCAA, 1995). On the other hand, African American women athletes graduate at a significantly higher rate than both African American men athletes (42\%) and African American women nonathletes (41\%).

Isolation and Alienation. Consistent with the person-environment fit conceptual framework, researchers have consistently delineated integration 
within the university setting as an important component of successful college student development (e.g., Bean \& Bradley, 1986; Nettles \& Johnson, 1987; Terenzini \& Pascarella, 1978; Tinto, 1975, 1987). Integration within the university community has been positively associated with academic performance for minority college student (Gosman, Dandridge, Nettles, \& Thoeny, 1983; Stoecker, Pascarella, \& Wolfle, 1988) as well as African American graduate students (Defour \& Hirsch, 1990). For African Americans, the racial climate of the environment significantly impacts their feelings of integration and subsequent behavior and well-being (Beckham, 1988; Rutledge, 1982; Sedlacek, 1987). Unfortunately, for many African American students the college environment can be both hostile and alienating. Suen (1983) found that African American college students report experiencing greater levels of alienation than White college students. Similarly, Allen (1988) noted that nearly half of his sample of African American students at six predominantly White universities reported feelings of alienation from the general campus life. Experiences with sexism may result in African American women having very different perceptions of the racial climate of their universities than African American men (Smith \& Stewart, 1983).

Along with being at risk for alienation and abuse as a result of their status as African American students, African American women student athletes also have to deal with the additional demands associated with participating in intercollegiate athletics. For instance, women student athletes spend approximately 25 hours a week in athletic-related activities (Center for the Study of Athletics, 1989b). Some researchers argue that these demands can help isolate student athletes from the rest of the campus environment (Adler \& Adler, 1991; Davis, 1990; Sellers, 1993). The time demands associated with intercollegiate athletics make it difficult for athletes to become involved in student activities outside of athletics which has been associated with positive student development (Boyer \& Sedlacek, 1988; Sedlacek, 1987). Feelings of isolation from the rest of the student body can result in poorer social and emotional development. As a result, student athletes' emotional and social development are often hampered (Petitpas, 1981).

Perceptions of Social Advantage As the Result of Athletics. Although the time demands associated with intercollegiate athletics may result in feelings of alienation, participation in intercollegiate athletics has also been related to positive personal development (Danish, Petitpas \& Hale, 1990; Duke, Johnson, \& Nowicki, 1987; Iso-Aloha \& Hatfeld, 1986; Picou \& Curry, 1974; Ryan, 1989; Sonestroem, 1982). Participation in intercollegiate athletics provides the opportunity to develop a number of skills which may enhance the personal competence of the student athlete (Danish, 1983). Benefits that athletes report receiving from their participation in intercol- 
legiate athletics include learning to make a commitment, the opportunity to travel, self-control, learning patience, and becoming disciplined (Danish, 1983). Also, Ryan (1989) found in a national sample of college students that those who participated in intercollegiate athletics reported greater motivation to earn a college degree, stronger interpersonal and leadership skills, as well as greater satisfaction with their overall college experience. With respect to women athletes, the Center for the Study of Athletics (1989b) reported that the majority of women student athletes feel that it easier for them as the result of being an athlete to learn new skills, learn about themselves, take on leadership responsibilities, and set and achieve personal goals. Participation in sports may result in the development of skills and competencies that are important in later life. In fact, some psychologists have hailed athletics as an important intervention for preventing and/or reducing at-risk behavior in youths (e.g., Agnew \& Peterson, 1989; Burling, Seidner, Robbins-Sisco, \& Krinsky, 1992; Cusson, 1989; Reppucci, 1987).

Satisfaction. Another potentially important area of the African American student athletes' college life experience is the extent to which she is satisfied. Because college athletes are required to perform the duties of both student and athlete, any assessment of their life satisfaction should include domain-specific assessments as well as an assessment of their overall satisfaction with life. With respect to measures of global satisfaction, the research literature suggests that athletes tend to report higher levels of satisfaction than nonathletes (Pascarella \& Smart, 1991; Ryan, 1989; Sellers et al., 1991). Sellers and his colleagues found that African American student athletes reported being more satisfied with life in general than African American nonathletes. In contrast, Pascarella and Smart (1991)'s study of male college athletes and nonathletes did not find a significant difference for African American student athletes and nonathletes in life satisfaction. However, they did find an overall difference in satisfaction between athletes and nonathletes. The discrepancy between the Pascarella and Smart (1991) and the Sellers et al. (1991) findings may result from the inclusion of African American women student athletes in the Sellers et al. study.

In sum, the research literature suggests that student athletes experience college in ways that are different from nonathletes. Many of these experiences are beneficial such as perceptions that they receive important inter- and intrapersonal competence as a result of their athletic participation. They also report that they are more satisfied than other college students with their lives. The research literature also suggests significant race and gender differences in the way in which student athletes experience college. With respect to academic performance Whites and women perform better than African Americans and men. Exposure to racism and sexism 
also differentially impact student athletes' experiences of social isolation and alienation. Unfortunately, as noted above, these findings do not directly address the experiences of African American women. It is the intent of the present study to address this oversight in the literature. An empirical descriptive analysis is utilized to investigate two interrelated questions. First, how do African American female student athletes experience college life? Second, do the life experiences of African American student athletes vary meaningfully as a function of gender and race? In other words, do African American female student athletes experience college differently from White female student athletes and African American male student athletes? A national sample consisting of African American female athletes, white female athletes, African American female nonathletes, and African American male athletes from 39 predominately white institutions are employed.

\section{METHOD}

\section{Sample}

The present study utilizes data from a 1987 survey of a national representative sample of 5,123 full-time undergraduate student athletes and students at Division I institutions commissioned by the President's Commission of the NCAA. The students were from 42 of the 291 Division I schools in 1987-1988 randomly sampled institutions. The national survey, conducted by the American Institutes for Research (AIR), also included two comparison groups of nonathletes: a sample of African American students and a sample of students involved in extracurricular activities. (For a more complete description of the sample, see Center for the Study of Athletics, 1988.) The present study examines only students from predominantly White institutions ( 39 of the 42 institutions sampled). Although there may be important differences between student athletes' experiences at these institutions and at predominately African American institutions, the fact that approximately $95 \%$ of the 302 NCAA Division I institutions are predominately white institutions justifies a focus on these institutions as an initial investigation. An examination of differences by racial composition of the institution is also prohibited by the small number of predominately African American institutions (3) that are include in the data set.

The sample for the present study consists of subsamples of African American female student athletes $(n=154)$, white female student athletes $(n=793)$, African American female nonathletic students $(n=250)$, and 
African American male athletes $(n=628)$ from the original study. The AIR data set does not report response rates by race and gender groups, thus we are unable to report a specific response rate for the subsample of the AIR data set which comprises the sample for the present study. However, the response rate for the entire AIR data set was reported as $75 \%$ (Center for the Study of Athletics, 1988).

In the present sample, approximately $75 \%$ of the African American female athletes were women's basketball players and the other $25 \%$ participated in nonrevenue producing sports. For white female athletes, the proportions were almost reversed: Approximately 35\% participated in women's basketball and $65 \%$ participated in nonrevenue sports. The distribution of sport participation is very different for African American and White athletes regardless of gender. African American athletes participate in the revenue-producing sports of football and men's and women's basketball at a rate that is greatly disproportionate to their population on campus, whereas they are underrepresented in the other nonrevenue sports (Center for the Study of Athletics, 1989a).

\section{Procedures and Measures}

Upon obtaining the informed consent of all respondents, students were administered questionnaires. The questionnaires for both the athletic and nonathletic groups were nearly identical in content but differed in their wording to correspond to respondents' group membership. The questionnaires elicited information on a variety of topics, including academic preparation, social background, personal and interpersonal experiences at college, expectations and attitudes regarding educational and career goals, and mental health. The present study investigates academic preparation, social background and four groups of variables reflective of the college life experiences of African American female athletes: These four groups of variables consist of academic performance; social isolation and alienation; perceived growth; and academic, athletic, and college life satisfaction. Factor analysis and principle components analysis were used to reduce data on various aspects of college life experience and to construct multiitem measures of students' college life experiences. Composite variables were constructed and analyzed using both raw scores and standardized scores. Because both methods yielded results that did not differ substantively from one another, the raw score composites are reported in order to simplify interpretation of the results.

Academic Preparation and Social Background. Two measures of academic preparation were used in the present study: students' self-reported 
high school grade point average (HSGPA) and scores on the Scholastic Aptitude Test (SAT). HSGPA was rated on an 8-point scale in which 1 represented a grade of $\mathrm{C}$ - or below and 8 represented an $\mathrm{A}$ or $\mathrm{A}+$ average. Students' combined verbal and math SAT scores were gathered from transcripts (SAT equivalent scores were computed for students who had only taken the ACT). Family income, occupational prestige, and parental education were standardized and averaged to construct a single composite measure of socioeconomic status (SES). When available, father's occupation level was coded using prestige scores from U.S. census codes; otherwise, mother's occupation was used. Students reported their parents' education levels on a 6-point scale in which 1 represented less than high school graduation and 6 represented having earned a postbaccalaureate degree (e.g., MA or PhD) (see Center for the Study of Athletics, 1988, for further details).

Academic Performance. Two indicators of collegiate academic performance were used. First, students' cumulative college grade point averages (college GPA) were collected from students' transcripts. Grades were calculated on a 4-point scale. The second indicator of academic performance was a composite variable of encompassing three types of academic difficulties: whether students had been placed on academic probation; repeated a class; or received an incomplete course grade since entering college. The total number of these incidents experienced were summed to create a measure of Academic Difficulties (the range of this scale was 0-3). Examination of these variables revealed weak to moderate negative correlations with college GPA $(r=-.15$ for incomplete grades, $r=-.24$ for repeating classes, and $r=-.32$ for academic probation, all $p<.01$ ), and a moderate multivariate relationship $\left(R^{2}=.12, p<.01\right)$. The composite variable of academic difficulties was moderately correlated with college GPA $(r=-.28, p<.01)$. The moderate relationships between these variables and college GPA suggest that it may be meaningful to view the construct of academic performance as multidimensional.

Isolation and Alienation. Isolation and alienation was measured as the extent to which students reported feelings of negative experiences on campus. High scores on these variables were seen as contributing to higher levels of isolation and alienation. Two composite variables were derived through principal components analyses of seven items in the questionnaire. The first composite variable was labeled Alienation/abuse (Cronbach's $\alpha$ $=.65$ ) and measured the extent to which students reported feeling a lack of control, feeling isolated, feeling sexual discrimination, feeling mental abuse and physical abuse. The second composite variable was labeled Racial tension (Cronbach's $\alpha=.85$ ) and measured the degree to which students experienced feelings of racial isolation and racial discrimination. 
Because reports of feeling racial isolation and racial discrimination were likely to have different meanings for African American versus White students, we did not examine comparisons across race (i.e., comparisons of African American women athletes vs. White women athletes) for the racial tension variable. Both composite scores were based on a response scale of 1 (never) to 4 (frequently).

Perceptions of Social Advantage As the Result of Athletics. Student athletes rated the extent to which it was easier or harder for them as an athlete to experience 20 activities associated with personal growth on a 5-point scale ranging from 1 (much easier) to 5 (much harder). Maximum likelihood factor analysis of the subsample included in the present study yielded a similar three-factor solution to an earlier analysis derived from the entire sample (see Sellers et al., 1991); thus the earlier composites were used in this study. Social skills $(\alpha=.83)$ measures student athletes' perceived difficulty or ease with items such as exercising self control, taking on leadership responsibilities, and learning from mistakes as a result of being an athlete. Opportunities $(\alpha=.74)$ includes items such as the student athletes' perception of the ease or difficulty in gaining opportunities to travel, display one's talents, earning praise, and interact with people of other races. Finally, Assertiveness $(\alpha=.72)$ measures students' perceived ease or difficulty with making decisions, getting dates, getting to know other students, and speaking one's mind. Comparisons between student athletes and nonathletes were not included because of differences in the wording of questions. Specifically, whereas student athletes were asked to rate the perceived personal development items with regard to their experiences as athletes, the African American nonathletes responded with regard to their experiences as students.

Academic, Athletic, and College Life Satisfaction. Principal components analysis was used to construct composite indices of satisfaction with three aspects of college life. Four items rated on a 4-point scale from 1 (dissatisfied) to 4 (satisfied) comprised a measure of Academic Satisfaction $(\alpha=.65)$. These items included students' satisfaction with their choice of major, with their courses, with their current course performance, and with their overall academic performance. Two items measuring satisfaction with coaching staff and satisfaction with sport personality $(r=.49)$ loaded on a factor labeled Athletic Satisfaction and scored on a 4-point scale from 1 (dissatisfied) to 4 (satisfied). (Note that athletic satisfaction was not examined in the comparison including African American women nonathletes.) Life Satisfaction was represented by a single item that elicited students' satisfaction with life in general ranging from 1 (dissatisfied) to 4 (satisfied). 
Plan of Analysis

Analyses were performed to examine mean differences between the target group of African American women athletes and each of the three comparison groups. Comparisons of African American women athletes versus White women athletes emphasize race differences in women student athletes' college life experiences. Comparisons of African American women athletes and nonathletes emphasize differences in the collegiate experiences of African American women who differ in athletic status. Finally, comparisons of African American female versus male athletes accentuate gender differences among African American student athletes. A series of multivariate analyses of variance (MANOVAs) were used to compare African American women athletes with the three comparison groups on SES, HSGPA, and SAT. Next, a series of multivariate analyses of covariance (MANCOVAs) were performed to compare African American women athletes' experiences in the four areas of college life with the experiences of the three comparison groups while partialling out the effects of the precollege variables of SES, HSGPA, and SAT by including them and all of their two-way interaction terms as covariates in all analyses. The influence of sport (revenue vs. nonrevenue) is partialled out by including such a variable as an independent variable in the race comparison analyses. Revenue sports were defined as women's basketball, men's basketball, and football. In all cases, race, athletic status, and gender differences on dependent variables are examined only when the multivariate $F$ for each MANOVA is significant at the $p<.01$ level.

\section{RESULTS}

\section{College Life Experiences of African American Women Student Athletes}

Table I summarizes African American women student athletes academic and demographic background as well as their college life experiences. The mean cumulative GPA for African American women athletes is 2.32. On average, African American women athletes report experiencing about one academic difficulty. African American women athletes' responses to the Alienation/abuse suggest that they almost never feeling alienated or abused. Similarly, African American women athletes report almost never experiencing racial isolation or incidents of racial discrimination. With regard to their perceived personal development, African American women athletes, on average, feel that it is somewhat easier for them to learn social skills, gain opportunities, and be more assertive as a result of their athletic 
Table I. Description of African American Women Athletes College Life

\begin{tabular}{|c|c|c|c|}
\hline & $M$ & $S D$ & Response range \\
\hline \multicolumn{4}{|l|}{ Academic performance } \\
\hline College GPA & 2.32 & 0.49 & $0.00-4.00$ \\
\hline Academic difficulties & 0.99 & 0.93 & $0.00-3.00$ \\
\hline \multicolumn{4}{|l|}{ Alienation and isolation } \\
\hline Feel alienation/abuse & 1.98 & 0.58 & $1=$ never to $4=$ frequently \\
\hline Feel racial tension & 1.89 & 0.80 & $1=$ never to $4=$ frequently \\
\hline \multicolumn{4}{|l|}{ Perceived personal growth } \\
\hline Social development & 2.48 & 0.56 & $1=$ much easier to $5=$ much harder \\
\hline Opportunities & 2.07 & 0.56 & $1=$ much easier to $5=$ much harder \\
\hline Assertiveness & 2.67 & 0.66 & $1=$ much easier to $5=$ much harder \\
\hline \multicolumn{4}{|l|}{ Satisfaction } \\
\hline Academic satisfaction & 2.88 & 0.52 & $1=$ dissatisfied to $4=$ satisfied \\
\hline Athletic satisfaction & 2.76 & 0.59 & $1=$ dissatisfied to $4=$ satisfied \\
\hline Life satisfaction & 3.22 & 0.54 & 1 = dissatisfied to $4=$ satisfied \\
\hline
\end{tabular}

status. African American women athletes seem somewhat satisfied with their academic and athletic situation. They also report being more satisfied than dissatisfied with their life in general.

\section{Demographic and Academic Background of African American Women Athletes and Comparison Groups}

Table II summarizes the results of analyses of demographic and academic background variables. African American women athletes' demographic and academic background differed from all three comparison groups. Compared to White women athletes (Multivariate $F=80.38, p<$ .01), African American women athletes came from poorer social backgrounds $(p<.01)$. African American women athletes' average score of 759.55 on the SAT was 166.19 points lower than White women athletes $(p$ $<.01$ ), and the average HSGPA reflected a $B$ average, compared to a $\mathrm{B}+$ average for White women athletes $(p<.01)$. A similar pattern of results emerged in comparing African American women athletes to African American women nonathletic students (Multivariate $F=12.71, p<.01$ ). African American women athletes had a lower mean SES level $(p<.05)$, earned lower high school grade point averages $(p<.05)$ and had SAT scores that were more than 100 points lower than African American women nonathletes $(p<.01)$. Compared to African American men athletes, however, a different pattern emerged (Multivariate $F=9.53, p<.01$ ). African Ameri- 
Table II. Results of MANOVA and ANOVA Analyses of Demographic and Academic Background Variables by Group ${ }^{a}$

\begin{tabular}{lcccc}
\hline & $\begin{array}{c}\text { Black women } \\
\text { athletes } \\
n=154\end{array}$ & $\begin{array}{c}\text { White women } \\
\text { athletes } \\
n=793\end{array}$ & $\begin{array}{c}\text { Black women } \\
\text { nonathletes } \\
n=250\end{array}$ & $\begin{array}{c}\text { Black men } \\
\text { athletes } \\
n=628\end{array}$ \\
\hline SES & $45.30(7.34)$ & $52.41(7.20)$ & $47.15(7.98)$ & - \\
HSGPA & $4.93(1.70)$ & $5.98(1.54)$ & - & $4.16(1.63)$ \\
SAT & $759.55(160.50)$ & $925.74(163.80)$ & $889.14(238.71)$ & - \\
$\begin{array}{l}\text { Wilks's } \lambda \\
\text { Multivariate } F\end{array}$ & - & $.80(F=80.38)$ & $.91(F=12.71)$ & $.96(F=9.53)$ \\
\hline
\end{tabular}

anly means $(S D)$ are reported for comparisons in which the main effect for group (race, gender, or athletic status) is significant at the $p<.05$ level and the overall $F$ for the ANOVA model is also significant at the $p<.01$ level.

can women athletes were similar to African American men athletes in terms of their social background and SAT scores, but differed in their HSGPA $(p<.01)$. African American women athletes earned higher high school grades (B) than did African American men athletes (B-).

\section{African American Female Athletes Versus White Female Athletes}

The results in Table III indicate that African American women athletes differed from their white counterparts on three of the nine comparisons that were examined (Multivariate $F=6.98, p<.01$ ).

Academic Performance. African American women athletes differed from White women athletes on both indices of college academic performance. African American women athletes earned lower grades than White women athletes $\left(F_{\text {total }}=21.95, p<.01\right)$. While the covariates (SE,S HSGPA, SAT composite score, participation in revenue sports, and their two-way interactions) accounted for a substantial proportion of the variance in college GPA $\left(F_{\text {covariates }}=21.31, p<.01\right)$, race differences persist after accounting for these effects $\left(F_{\text {race }}=23.32, p<.01\right)$. Examination of the academic difficulties composite revealed a similar pattern. African American women athletes reported experiencing 0.99 of three indices of academic difficulties, compared to 0.42 for White women athletes $\left(F_{\text {race }}=12.72, p\right.$ $<.01$ ). Once again, the covariates accounted for a significant proportion of the variance in academic difficulties $\left(F_{\text {covariates }}=18.24, p<.01\right)$.

Isolation and Alienation. African American and white women athletes reported similar levels of alienation/abuse. Both groups reported that ex- 
periences of alienation/abuses had occurred "rarely (about 1 to 5 times since being at school)." Feelings of alienation/abuse were significantly related to the covariates $\left(F_{\text {covariates }}=4.33, p<.01\right)$. No group comparisons were examined for feeling racial tension (see above).

Perceptions of Social Advantage as the Result of Athletics. Generally, both African American and white women athletes reported that their experiences as athletes facilitated their personal development. These groups did not differ in the extent to which they reported ease with gaining social skills or in the extent to which they reported that it was easier for them to gain opportunities as a result of their status as athletes. Both groups reported that as athletes it is "easier/no difference" to develop social skills and to gain opportunities as a result of being an athlete. African American women athletes reported that it was easier to gain assertiveness skills than did White women athletes $\left(F_{\text {race }}=8.89, p<.01\right)$. The covariates also explained a significant proportion of the variance in perceptions of gaining assertiveness skills as a result of participation in athletics $\left(F_{\text {covariates }}=\mathbf{2 . 5 0}\right.$, $p<.01)$.

Academic, Athletic, and Life Satisfaction. Although there appear to be some observed differences in the levels of satisfaction that African American and White women athletes report, these differences appear to be a function of race differences in the covariates used in the analysis. Race was not a significant main effect for any of the three areas of satisfaction. However, the covariates were significant predictors of academic satisfaction $\left(F_{\text {covariates }}=9.74, p<.01\right)$, athletic satisfaction $\left(F_{\text {covariates }}=10.42, p<.01\right)$, and life satisfaction $\left(F_{\text {covariates }}=2.43, p<.01\right.$ ), respectively.

\section{African American Female Athletes Versus African American Male Athletes}

Table III also summarizes the results of the comparison of African American women versus men athletes. African American women athletes differed from African American men athletes on 3 of the 10 areas of college life experiences that were examined (Multivariate $F=5.65, p<.01$ ).

Academic Performance. African American women athletes differed from African American men athletes on one of the two indicators of academic performance. African American women athletes had higher college GPAs than their male counterparts $\left(F_{\text {gender }}=8.17, p<.01\right)$. However, no gender differences were found in the number of academic difficulties. Also, the covariates (SES, HSGPA, SAT composite score, and their two-way interactions) accounted for a significant proportion of the variance in student athletes' college GPA ( $F_{\text {covariates }}=9.64, p<.01$ ) and academic difficulties $\left(F_{\text {covariates }}=7.41, p<.01\right)$. 
Table III. Results of MANOVA and ANOVA Analyses of College Life Experiences by Group $^{a}$

\begin{tabular}{|c|c|c|c|c|}
\hline & $\begin{array}{c}\text { Black } \\
\text { women } \\
\text { athletes } \\
M \quad(S D)\end{array}$ & $\begin{array}{c}\text { White } \\
\text { women } \\
\text { athletes } \\
M \quad(S D)\end{array}$ & $\begin{array}{c}\begin{array}{c}\text { Black } \\
\text { men }\end{array} \\
\text { athletes } \\
M \quad(S D)\end{array}$ & $\begin{array}{c}\text { Black } \\
\text { women } \\
\text { nonathletes } \\
M \quad(S D)\end{array}$ \\
\hline \multicolumn{5}{|l|}{ Academic performance } \\
\hline College GPA & $2.32(0.49)$ & $2.80(0.56)$ & $2.14(0.44)$ & - \\
\hline Academic difficulties & $0.99(0.93)$ & $0.42(0.72)$ & - & - \\
\hline \multicolumn{5}{|l|}{ Alienation and isolation } \\
\hline Feel alienation/abuse & $1.98(0.58)$ & - & - & - \\
\hline Feel racial tension & $1.89(0.80)$ & na & $2.22(0.94)$ & - \\
\hline \multicolumn{5}{|l|}{ Perceived personal growth } \\
\hline Social development & $2.48(0.56)$ & - & - & na \\
\hline Opportunities & $2.07(0.56)$ & - & - & na \\
\hline Assertiveness & $2.67(0.66)$ & $2.81(0.58)$ & $2.38(0.73)$ & na \\
\hline \multicolumn{5}{|l|}{ Satisfaction } \\
\hline Academic satisfaction & $2.88(0.52)$ & - & - & - \\
\hline Athletic satisfaction & $2.76(0.59)$ & - & - & - \\
\hline Life satisfaction & $3.22(0.54)$ & - & - & - \\
\hline Wilk's lambda for group & & $.94(F=6.93)$ & $.93(F=5.61)$ & $.91(F=6.40)$ \\
\hline
\end{tabular}

${ }^{a}$ Only means $(S D)$ are reported for comparisons in which the main effect for group (race, gender, or athletic status) is significant at the $p<.01$ level and the overall $F$ for the ANOVA and MANOVA models are also significant at the $p<.01$ level.

Isolation and Alienation. The covariates were significant predictors of alienation/abuse $\left(F_{\text {covariates }}=2.58, p<.05\right)$, however no gender differences were found in alienation/abuse. With regard to racial tension, gender differences were found $\left(F_{\text {gender }}=9.14, p<.01\right)$. Although both groups reported "rarely" feeling racial tension, African American men athletes reported feeling racial tension more often than African American women athletes. The covariates did not account for a significant proportion of the variance in racial tension.

Perceptions of Social Advantage as the Result of Athletics. Men and women African American athletes perceived similar levels of ease with social development and gaining opportunities as a result of being athletes. For gaining social skills and opportunities, both groups felt that being an athlete made no difference in these aspects of their personal development. However, gender differences were found with respect to their perception of the ease to which they could obtain assertiveness skills as a result of being an athlete $\left(F_{\text {gender }}=20.10, p<.01\right)$. African American women ath- 
letes were less likely to report that being an athlete made gaining assertiveness skills somewhat easier than African American men athletes. The covariates were not significant predictors of any of the three perceived personal development indicators.

Academic, Athletic, and Life Satisfaction. African American men and women athletes reported similar levels of academic, athletic, and life satisfaction. Women athletes and men athletes reported being "more satisfied than dissatisfied" with life in general. Mean scores for both groups on academic and athletic satisfaction suggest some ambivalence, falling slightly below the response range for "more satisfied than dissatisfied" The covariates were not significant predictors of any of the areas of satisfaction.

\section{African American Female Athletes Versus African American Female Nonathletes}

Table III summarizes the results of the comparison of African American women athletes and African American women nonathletes. Although there was a significant multivariate effect for the models comparing African American women athletes and nonathletes (Multivariate $F=6.40, p<$ .01 ), this effect seems to be driven by the relationship between the covariates (SES, HSGPA, SAT composite score, and their two-way interactions) and the dependent variables. There was no significant group differences for any of the individual dependent variables when the effects of the covariates were partialled out. The covariates were significant predictors of both college GPA $\left(F_{\text {covariates }}=4.31, p<.01\right)$ and academic difficulties $\left(F_{\text {co. }}\right.$ variates $=4.70, p<.01)$.

\section{DISCUSSION}

The present study had two objectives. The first was to provide a descriptive analysis of the life experience of African American women student athletes. Our results suggest that in terms of academics, African American women athletes are performing adequately considering the time demands associated with athletics and their poorer academic preparation. Although there is certainly room for improvement, African American women athletes perform, on average, above most institutions' minimal GPA requirements (2.0) for good academic standing. They also do not experience multiple academic problems such as repeating courses, receiving incomplete grades, or being placed on probation. On average, African American women athletes reported almost never experiencing alienation or abuse. Although they 
reported more racial isolation than White women athletes and lower than African American men, the level of racial isolation reported also was in the "rarely" range of response. Of course, one could argue that experiencing incidents of racial tension only rarely is still too often.

With regard to their perceived personal development, African American women athletes seem to believe that their athletic status provides them with a greater opportunity to learn social skills, gain opportunities, and be more assertive. Their perceptions of enhanced social advantage as a result of athletics are consistent with the work of Danish and his colleagues (Danish, 1983; Danish, et al., 1990) who suggest that participation in organized athletics may actually enhance the development of personal competence. It should be noted that although African American women athletes view athletic participation as facilitating their personal development, the present study did not measure whether they actually had a relatively easier time developing or the extent of development that actually occurred. We measured only their perceptions of growth. Consistent with their somewhat positive profile in other areas of college life, African American women athletes seem to be satisfied with their college experience. Their satisfaction with their academic performance appears to be linked to relatively high expectations and reasonable assessments of their current academic status. They also seem to be somewhat satisfied with their athletic performance. As a whole, African American women athletes seem to enjoy a somewhat positive collegiate experience.

Our second objective was to examine whether African American women athletes' college life experiences differ significantly from White women athletes and African American men athletes. Our results suggest that even after accounting for background differences, African American women student athletes college life experiences differ in meaningful ways from both White women studentathletes and African American men student athletes. With regard to academic performance, African American women student athletes perform less well than White women student athletes but achieved higher GPAs than African American men student athletes. African American and White women athletes report similar experiences with regard to social integration. Both African American and White women athletes report relatively low levels of alienation and abuse.

African American women athletes also reported experiencing less racial tension than their African American men counterparts. This finding is consistent with those of Fleming $(1983,1984)$, who concluded that African American women college students were able to fair better academically and interpersonally on a predominantly White campus than their African American men counterparts. Some authors have argued that African American men are perceived as posing a greater threat to the White social 
structure than African American women and therefore, are at greater risk within the current social structure (Staples, 1991). Although we did not directly test this hypothesis, our findings that African American women student athletes performed stronger academically and reported lower levels of perceived racial tension than their African American men counterparts are consistent with such an interpretation.

With regard to perceptions of social advantage, African American women athletes perceive that their athletic status is more beneficial to learning assertiveness skills than do White women athletes, but they do not report as great a benefit as African American men athletes. One interpretation of this finding is that assertive behavior has traditionally been viewed as more socially appropriate among males than among females. African American women athletes, being a "double minority," may be more sensitive compared to White women athletes to the notion that the role of athlete affords a greater opportunity for their assertive behavior to be viewed as socially appropriate. Fleming $(1983,1984)$ found that African American women college students were more assertive on a predominantly White campus than on a historically African American campus as a result of there being fewer African American men around. Thus, the African American women take on more assertive roles that are usually fulfilled by African American men when there is a dearth of men. Meanwhile, another interpretation argues that because African American females have traditionally played a more assertive role in all facets of family life (Albert \& Porter, 1988; Myers, 1989), they may be more familiar than White females with the increased opportunities to be assertive that may be afforded by the role of athlete.

Interestingly, the college life experiences of African American females seem to be comparable regardless of whether or not they participate in intercollegiate athletics. Although African American women athletes and African American women nonathletes come from different backgrounds, they reported similar experiences across the three areas of college life which were examined. Whereas African American women athletes had significantly lower college GPAs and more academic problems than the African American women nonathletes, these differences were accounted for by academic preparation and demographic background differences. An interesting question is whether or not African American women athletes and nonathletes perceived similar levels of personal development. As mentioned previously, the items used in the questionnaire do not allow such an analysis. Nonetheless, the similarities in the other areas of college life experience suggest that participation in athletics for African American women athletes does not seem to influence their experiences as much as race and gender. However, further research is needed before a definitive 
statement regarding the relative importance of race, gender, and athletic status can be assessed.

There are limitations to the present study which suggest that the results should be interpreted with caution. First, all the data in this study were collected from self-reports. The extent to which participants responses were influenced by social desirability is unknown. Also, the study represents student athletes' experiences, attitudes, and beliefs at only one period of time. Thus, it is impossible to capture the potential dynamic nature of their experience. For instance, it is plausible that the African American women athletes may have a different developmental trajectory during their college tenure than other groups of students. Longitudinal data are needed before such an analysis can occur. Despite these limitations, the present study provides an important foundation upon which further research can build. It focuses on a population that has been virtually ignored by the research literature.

\section{Policy Implications}

The present study serves as a baseline from which to evaluate the impact of potential policy changes in the future. The present results also speak tangentially to the current debate regarding increased academic standards for incoming first-year student athletes. In general, African American women athletes are doing relatively well academically in comparison to African American men athletes. Despite the differences in college GPA, African American women athletes have similar SAT scores and come from similar socioeconomic backgrounds as African American male student athletes. These results call into question the predictive value of the SAT composite score for the academic performance of African American student athletes (Sellers, 1992). The present results suggest that the use of HSGPA as a criterion for initial athletic eligibility may be preferential to the use of SAT composite score (Sellers, 1992). However, more in-depth analyses are needed before a definitive policy recommendation can be made.

The high concentration of African American women athletes in the revenue-producing sports of women basketball has implications for the enforcement of Title IX at the collegiate level. Many institutions have added women sports and cut men's sport as a way of complying with Title IX. Most of these sports tend to have very few African American women who participate (e.g., women's crew). There is some concern that African American women athletes will not benefit from the increased opportunities that may occur as a result of the enforcement of Title IX at the collegiate level unless they are provided with greater access and exposure to these 
"new" sports at the high school and recreational level (Corbett \& Johnson, 1993). Nonetheless, African American women still have less access to collegiate athletics than African American men as evidenced by the far smaller percentage of African American women receiving athletic scholarships (2\%) as compared to African American men receiving athletic scholarships (11 \%: NCAA, 1995).

In conclusion, the present study represents an effort to examine the ecological experiences of the African American women student athletes. Such an effort is consistent with Sellers (1993) argument that policy makers interested in improving the academic performance of student athletes should focus more on the college life experiences of student athletes. The present study also provides baseline data on the unique experiences of African American women athletes from which to evaluate the impact of potential policy changes. Finally, we hope that the present study will spur other investigators to recognize that African American women athletes are a sample population worthy of study in and of itself.

\section{REFERENCES}

Adler, P., \& Adler, P. (1991). Back boards and blackboards: College athletics and role engulfment. New York: Columbia University Press.

Agnew, R., \& Peterson, D. M. (1989). Leisure and delinquency. Social Problems, 36, 332-350.

Albert, A. A., \& Porter, J. R. (1988). Children's gender-role stereotypes: A sociological investigation of psychological models. Sociological Forum, 3, 184-210.

Allen, W. R. (1985). Black student, white campus: Structural, interpersonal, and psychological correlates of success. Journal of Negro Education, 54, 134-147.

Allen, W. R. (1988). Black students in U. S. higher education: toward improved access, adjustment and achievement. Urban Review, 20, 165-188.

Bean, J. P., \& Bradley, R. K. (1986). Untangling the satisfaction-performance relationship of college students. Joumal of Higher Education, 57, 393-412.

Beckham, B. (1988). Strangers in a strange land: The experiences of Blacks on White campuses. Educational Record, 68, 74-78.

Bell, R. Q. (1986). Age specific manifestations in changing psychosocial risk. In D. C. Farran \& J. D. Mckinney (Eds.), Risk in intellectual and psychosocial development (pp. 169-183). New York: Academic Press.

Bird, A. M., \& Cripe, B. K. (1986). Psychology and sport behavior. St. Louis, MO: Times/Mosby.

Boyer, S. P., \& Sedlacek, W. E. (1988). Noncognitive predictors of academic success for international students: a longitudinal study. Joumal of College Student Development, 29, 218-223.

Bronfenbrenner, U., \& Crouter, A. C. (1982). Work and family through time and space. In S. B. Kamerman \& C. D. Hayes (Eds.), Families that work: Children in a changing environment of work, family, and community. Washington, DC: National Academy of Science.

Burling, T. A., Seidner, A. L, Robbins-Sisco, D., \& Krinsky, A. (1992). Relapse prevention for homeless veteran substance abusers via softball team participation. Journal of Substance Abuse, 4, 407-413.

Center for the Study of Athletics (1988). Report No. 2: Methodology of the 1987-88 national study of intercollegiate athletes. Palo Alto, CA: American Institutes for Research. 
Center for the Study of Athletics (1989). Report No. 3: The experiences of black intercollegiate athletes at NCAA division I institutions. Palo Alto, CA: American Institutes for Research.

Center for the Study of Athletics (1989). Report No. 4: Women in intercollegiate NCAA division I institutions. Palo Alto, CA: American Institutes for Research.

Corbett, D., \& Johnson, W. (1993). The African-American female in collegiate sport: Sexism and racism. In D. Brooks \& R. Althouse (Eds.), Racism in college athletics: The African American athlete's experience, Morgantown, WV: Fitness Information Technology, Inc.

Cusson, M. (1989). Disputes over honor and gang aggression, Revue Internationale de Criminologie et de Police Technique, 42, 290-297.

Danish, S. J. (1983). Musings about personal competence: the contributions of sport, health and fitness. American Journal of Community Psychology, 11, 221-240.

Danish, S. J., Petitpas, A. J., \& Hale, B. D. (1990). Sport as a context for developing competence. In T. P. Gullotta, G. R. Adams, \& R. Montemayor (Eds.), Developing social competency in adolescence. Newbury Park, CA: Sage.

Davis, J. A. (1990). Researcher issues and strategies in regard to the educational treatment of the black athlete. Paper presented at the meeting of the Southern Association for Institutional Research and the Society for College and University Planning, Fort Lauderdale, Fl.

Defour, D. C., \& Hirsch, B. J. (1990). The adaptation of black graduate students: A social network approach. American Journal of Community Psychology, 18, 487-503.

Duda, J. L., \& Allison, M. T. (1990). Cross-cultural analysis in exercise and sport psychology: A void in the field. Journal of Sport and Exercise Psychology, 12, 114-131.

Duke, M., Johnson, T. C., \& Nowicki, S. Jr. (1987). Effects of sport fitness camp experiences on locus of control orientation in children ages 6-14. Research Quarterly, 48, 280-283.

Ervin, L., Saunders, S.A., Gillis, H. L., \& Hogrebe, M. C. (1985). Academic performance of student athletes in revenue-producing sports. Journal of College Student Personnel, 26, 119-124.

Evans, V., \& Quarterman, J. (1983). Personality characteristics of successful and unsuccessful black female basketball players. Intemational Journal of Sports Psychology, 14, 105-115.

Fleming, J. (1983). Black women in black and white college environments: The making of a matriarch. Joumal of Social Lssues, 39, 41- 54.

Fleming, J. (1984). Blacks in college. San Francisco: Jossey-Bass.

Gosman, E. J., Dandridge, B. A., Nettles, M. T., \& Thoeny, A. R. (1983). Predicting student progression: the influence of race and other student and institutional characteristics on college student performance. Research in Higher Education, 18, 209-236.

Iso-Aloha, S., \& Hattield, B. (1986). Psychology of Sports: $\boldsymbol{A}$ social psychological approach. Dubuque, IA: Wm. C. Brown.

Kiger, G., \& Lorentzen, D. (1986). The relative effect of gender, race, and sport on university academic performance. Sociology of Sport Joumal, 3, 160-167.

Loo, C. M., \& Rolison, G. (1986). Alienation of ethnic minority students at a predominantly White university. Joumal of Higher Education, 57, 59-77.

McArdle, J. J., \& Hamagami, F. (1994). Logit and multilevel logit modeling of college graduation rates for 1984-85 freshman student athletes, Joumal of the American Statistical Association, 89, 1107-1123.

Myers, L. W. (1989). Early gender role socialization among black women: Affective or consequential? Westem Joumal of African American Studies, 13, 173-178.

National Collegiate Athletic Association (1991). A statistical analysis of the predictions of graduation rates for college student athletes. NCAA Research Report \#91-02. Overland Park, KA: Author.

National Collegiate Athletic Association (1995). 1995 NCAA division I graduation-rates report. Overland Park, KA: Author.

Nettles, M. T., \& Johnson, J. R. (1987). Race, sex and other factors as determinants of college students' socialization. Joumal of College Student Personnel, 28, 512-524.

Pascarella, E. T., \& Smart, J. C. (1991). Impact of Intercollegiate Athletic Participation for African American and Caucasian Men: Some Further Evidence. Joumal of College Student Development, 32, 123-129. 
Petitpas, A. (1981). The identity development of the male intercollegiate athlete. Unpublished doctoral dissertation, Boston University.

Picou, J. S., \& Curry, E. W. (1974). Residence and the athletic participation-educational aspiration hypothesis. Social Science Quarterly, 55, 768-776.

Prakasa Rao, V., \& Overman, S. (1984). Sex-role perceptions among Black female athletes and nonathletes. Sex Roles, 11, 601-614.

Purdy, D., Eitzen, D. S., \& Hufnagel, R. (1982). Are athletes also students? The educational attainment of college athletes. Social Problems, 29, 439-448.

Reppucci, N. D. (1987). Teen-age pregnancy, child sexual abuse, and organized youth sports. American Joumal of Community Psychology, 15, 1-22.

Rutledge, E. M. (1982). Students' perceptions of racism in higher education. Integrated Education, 20, 106-111.

Ryan, F. J. (1989). Participation in intercollegiate athletics: affective outcomes. Journal of College Student Development, 30, 122-128.

Sedlacek, W. E. (1987). Black students on White campuses: 20 years of research. Journal of College Student Personnel, 28, 484-495.

Seidman, E. (1991). Growing up the hard way: Pathways of urban adolescents. American Journal of Community Psychology, 19, 173-201.

Sellers, R. M., Kuperminc, G. P., \& Waddell, A. S. (1991, Fall). Life experiences of African American student athletes in revenue producing sports: A descriptive empirical analysis. Academic Athletic Joumal, 21-38.

Sellers, R. M. (1992). Racial differences in the predictors of academic achievement of Division I student athletes. Sociology of Sport Joumal, 9, 48-59.

Sellers, R. M. (1993). Black student athletes: Reaping the benefits or recovering from exploitation? In D. Brooks and R. Althouse (Eds.), Racism in College Athletics, Morgantown, WV: Fitness Information Technology.

Shapiro, B. J. (1984). Intercollegiate athletic participation and academic achievement: A case study of Michigan State University student athletes, 1950-1980. Sociology of Sport Journal, $1,46-51$.

Smith, A., \& Stewart, A. J. (1983). Approaches to studying racism and sexism in Black women's lives. Joumal of Social Issues, 39, 1-15.

Sonestroem, R. J. (1982). Exercise and self esteem: Recommendations for expository research. Ouest, 33, $124-139$.

Stage, F. K. (1988). Reciprocal effects between the academic and social integration of college students. Research in Higher Education, 30, 517-530.

Stage, F. K. (1989). Motivation, academic and social integration, and the early dropout. American Educational Research Joumal, 26, 385-402.

Staples, R. (1991). Black male genocide: A final solution to the race problem in America. In B. J. Bowser (Ed.), Parenting and education in community context, Lanham, MD: University Press.

Stoecker, J., Pascarella, E. T., \& Wolfle, L. M. (1988). Persistence in higher education: A 9-year test of a theoretical model. Joumal of College Student Development, 29, 126-209.

Suen, H. K. (1983). Alienation and attrition of Black college students on a predominantly White campus. Joumal of College Student Personnel, 24, 117-121.

Terenzini, P. T., \& Pascarella, E. T. (1978). The relation of students' precollege characteristics and freshman year experience to voluntary attrition. Research in Higher Education, 9, 347-366.

Tinto, V. (1975). Dropout from higher education: A theoretical synthesis of recent research. Review of Educational Research, 45, 89-125.

Tinto, V. (1987). Leaving college: Rethinking the cause and cures of student attrition. Chicago: University of Chicago Press.

Tracey, T. J., \& Sedlacek, W. E. (1984). Noncognitive variables in predicting academic success by race. Measurement and Evaluation in Guidance, 16, 171-178. 